\title{
Central Lancashire New Town: The hidden polycentric supercity
}

\author{
Victoria Jolley \\ Manchester School of Architecture. UK \\ E-mail: v.jolley@mmu.ac.uk
}

\begin{abstract}
From 1962 Lancashire, in England, became the focus of a major renewal scheme: the creation of a 'super-city' for 500,000 people. The last and largest New Town designated under the 1965 Act, Central Lancashire New Town (CLNT) differed from other New Towns. Although influenced by the ideals and example of Garden City model, its master plan followed new and proposed infrastructure to connect the sub-region's poly-centricity. By unifying and expanding existing towns and settlements it aimed to generate prosperity on a sub-regional scale using the New Towns Act, rather than creating a single new self-sufficient urban development. CLNT's scale, poly-centricity and theoretical growth made it unique compared to other new town typologies and, although not realised, its planning can be traced across Lancashire's urban and rural landscape by communication networks and city-scale public and civic buildings. With reference to diagrams for the British New Towns of Hook, Milton Keynes and Civilia, this paper will contextualize and evaluate CLNT's theoretical layout and its proposed expansion based on interdependent townships, districts and 'localities'. The paper will conclude by comparing CLNT's theoretical diagram with its proposed application and adaptation to the sub-region's topographical physical setting.
\end{abstract}

Keywords: Lancashire, New Towns, urban centres and pattern

Designated in 1970 Central Lancashire New Town is significant because it was the last and largest of the third generation new towns proposed in Britain between 1967 and 1970 and it demonstrated an unprecedented application of the New Town Act. Set within rural Lancashire, CLNT is a part-realised subregional complex based on an interconnected series of urban townships. Inspired by the context's existing poly-centricity, it focused on small towns and villages surrounding Preston, Chorley and Leyland and involved the creation of substantially new communities as well as the controlled expansion of existing settlements. Prepared by Central Lancashire Development Corporation following extensive consultation, its strategy for delivery over a period of 30 years was released prior to a public inquiry as an Outline Plan in 1974 (Pearson, 1974). This master-plan prepared by Robert Matthew Johnson Marshall and Partners accommodated a predicted population increase from 253,000 in 1966 to 503,000 in 1991 over 51,460 acres, 44,187 acres of which had been identified as suitable for development. Four key criteria needed to be satisfied - the integration of new and existing developments to promote urban renewal including raising the quality of existing development and maintaining a clear contrast between town and country; the phasing of construction in self-contained locations which have appropriate urban character; the integration of all forms of private and public transport, whilst segregating vehicles and pedestrians; land use should accommodate changing circumstances and eventual growth 
beyond the predicted population intake but not necessarily within the designated area.

The concept of planned decentralization to relieve Britain's inner city overcrowding had been introduced in 1940 by the Barlow Report but it was not until after the Second World-War that the principle of population displacement to facilitate the redevelopment of Britain reignited interest in new towns. A New Towns Committee, established in 1945, considered their delivery and configuration and the passing of two revolutionary Acts - the New Towns Act 1946 and the Town and Country Planning Act 1947, followed. The first series of new towns, the Mark 1's (1946 - 1961), were low density, self-sufficient, satelite extensions of their parent conurbations. An example, Harlow (1947), designed by Frederick Gibberd (1908-1984), is an experimental town designed to accommodate an independent isolated community of 50,000 people 23 miles from London (Rodwin, 1956). Influenced by Ebenezer Howard's Garden City ideas, Harlow's layout was characterised by its civic core surrounded by defined neighbourhoods, each with a local centre. Probably informed Raymond Unwin's (1863 - 1940) garden suburbs achieved prior to the First-World War, Harlow's layout had been prepared based on the theory that a modern town's individual character should be informed by its site's topography and natural features. Main means of transport (road, rail and water) followed the line of a valley along the north site boundary and this was overlooked by thirteen small housing clusters, each separated by landscape. Two industrial areas, sited in close proximity to main communication lines, were disected by the outer radial road system that, by being intersected by roads at right angles, aimed to provide direct access from the central core to the neighbourhoods (Gibberd, 1947).

In the County of Lancashire the requirement for a regional strategy to accommodate Manchester's overspill had existed since 1947 and Leyland had been repeatedly identified as a potential Mark 1 new town. It was considered favourable due to its good communications to Manchester via north-south rail routes and the proposed M6 motorway. It also had high levels of employment in the motor manufacturing industry, primarily at British Leyland, and land availability to provide residential areas and amenities (Lancashire archives, 1968). By 1951 the Preliminary Plan for Lancashire had included Leyland as one of three new towns across the northwest region and had proposed that, by accommodating 32,900 people mainly around Worden Park, Leyland's population could be trebled. The Preliminary Plan included a map that indicates Leyland's proposed layout conformed to the Mark 1 formula, as demonstrated at Harlow. The proposed M6 motorway restricted its eastern edge and connected to a radial peripheral road system that linked two industrial areas. Despite being included in the Preliminary Plan, the three new towns at Parbold and Garstang, Leyland were later omitted from the approved Lancashire County Council's development plan of 1956.

Because the Mark 1 new towns proved to be too suburban in character, the second wave, the Mark 2s (1961 - 1966), intensified use by being larger and denser. Although not accomplished, the layout for the new town at Hook (1961), based on the planning of Cumbernauld, remained influential throughout the 1960s. At less that one mile wide and with a predicted final population of 100,000 , its concept was a compact city in a garden. Separate neighbourhoods, as witnessed in the Mark 1 towns were abandoned and replaced by a dominant central hub in a linear configuration. Rather than working with the topography as seen in Harlow, a pedestrianised lid covered the valley to segregate pedestrian and vehicular movement. This provided a platform for high-density urban housing for 60,000 residents surrounded open space and, to offer choice, civic amenities were duplicated at frequent intervals. Residential privacy was achieved by offering low single-aspect housing with gardens opening onto walkways. Outside the core, concentric bands of residential areas with decreasing density met a green belt of recreation space. Underneath the pedestrianised deck a sub-terranian grid of distributor roads linked the new town to the regional road network, the town's three peripheral industrial areas and its parking for 800 cars (Architects' Journal, 1961). 
The third generation new towns (196770) explored the potential of multiple urban or neighbourhood centres to reinforce unity. Milton Keynes (1967) and Central Lancashire New Town (1970) are two examples that adopted this principle through different urban diagrams. Milton Keynes was designed to accommodate a population increase from 44,000 to 250,000 by the turn of the century. Spanning rolling Buckinghamshire farmland, it is located on the main high-speed railway and motorway between the North of England and London. It's net and fill layout based on a one-kilometre grid of two-lane roads promoted dispersal and the spread of vehicular traffic across the town was encouraged by scattering employment, education, health facilities, recreation, housing and retail. Two parklands weave through the city and cycleways link urban layouts with landscape. There were no defined self-sufficient neighbourhoods, instead each area defined by the lattice was treated as an individual place for 5,000 people, known as a township, and local centres were positioned to form high streets where adjacent places touch. The initial phase, planned to be completed by 1980 , adopted a linear format running north to south with a spur to the east to link an industrial area with the M1 motorway. This concentrated growth on the existing towns of Bletchley, Wolverton and Stony Stratford, allowing them to unify first (Bendixson, 1969). Simultaneously the idea of inter-related growth was being explored in Lancashire by exploiting the region's existing towns' interdependency and expanding or strategically injecting centres along key communication routes to ensure residential and industrial areas were distributed to minimise peak journeys. Proposals were based on the work of Scottish architects Hugh Wilson and Lewis Womersley who, by experimenting with forms of linear expansion at Northampton (1968), had promoted a three-strand system based on wide bands of development along lines of communication. By 1960 Manchester and Merseyside's tremendous overspill problems had only been partly solved by neighbouring counties and local authorities receiving population and it was not long until the discussion of a new town at Leyland for Manchester and also Preston reignited (Brooke,
1960). In 1964 the County Planning Officer prepared a 'Preliminary Technical Report on the Future of Central mid-Lancashire' that focused on the Preston-Chorley-Leyland area (Coates, 1964). At the time Preston was an administrative and communications centre serving a wide hinterland with its port, service industry and retail facilities. Chorley was a compact small self-sufficient market town with parkland to the West and Rivington Reservoirs and Anglezance Moors to the east. Leyland had experienced rapid incoherent growth as an important flourishing manufacturing and industrial town. The three towns had a combined population of 250,000 and all were in close proximity to improved north/ south main infrastructure routes.

Similar to Ebenezer Howard's utopian objectives, the preliminary report described a pattern of land use that aimed to provide wellpositioned and sufficient industry, open space, compact amenities and public services. Journey times could be limited to 30 minutes to open country, 20 minutes to work and 10 minutes to local shops and school. The following year Richard Crossman, then Minister of Housing and Local Government, commissioned Robert Matthew Johnson Marshall and Partners (RMJM) to develop the technical report and undertake preliminary studies for a fourth new town at central Lancashire. Entitled Study for a City, the report marks a long evolutionary process and period of consultation to determine the location and form of the new town as well as its impact on adjacent settlements. Defined by agricultural belts to the north and west, hills and moors to the east and Wigan's coalfield to the south, the geographical area, the 'subregion', considered for the designation area included Preston, Leyland and Chorley and was dissected by the M6 and M61 motorways.

CLNT's sub-regional strategy underwent three stages of refinement. Initially RMJM's proposals are a diagrammatic, represented out of context as a theoretical urban pattern that aimed to balance the growth of employment, housing and transport and reinforce the social, economic and geographical characteristics of Lancashire. The notional urban pattern was based on four community types of differing scales: the entirety, the city $(300,000-500,000$ 
people); townships $(60,000-80,000)$; districts $(15,000-18,000)$ and localities $(4,000-5,000)$. Arranged as a linear ladder-like complex the initial format comprised seven inter-connected townships connected by a three-strand system of dual carriageways and public transport routes to promote evenly distributed freeflowing travel with minimal congestion. A framework of green belts and woodland would define each community's individuality as well as create visual barriers between housing and employment areas. It also provided a network of footpaths between open spaces and the countryside. RMJM proposed a multicentred growth strategy to disperse economy, employment and amenities throughout the city, giving each area a clear function and equal potential. This was thought to be advantageous as the array and number of facilities could increase in line with population growth. Dual carriageways linked the township's residential and industrial areas to the motorway and an express bus route joined the centres. Within the townships distributor single carriageways enabled lateral and radial vehicular movement between industrial and residential quarters and the town centre. This was supplemented by local public transport supported by a town's central interchange with car parking. Multiple pedestrian routes linked the town centre, its park, districts and outer recreational space. Infrastructure also separated the township's inner core (the nucleus occupied by the town centre, parkland and smaller community districts with local amenities) from an outer ring of further districts including industry located on the periphery.

RMJM's initial scheme for CLNT adopted Wilson and Womersley's initial approach for industry and infrastructure and also based the districts' layout on a superblock model that segregated pedestrian and vehicular movement. Each district had centrally positioned local community facilities such as schools, nurseries and greens that were accessed by footpaths and public transport, with industry positioned adjacent to main roads. New urban housing respected the urban grain and included blocks of two-storey maisonettes mixed with smaller units, concealed ground-floor car parking and pedestrian access above. Similar to Hook, the challenges of undulating rural landscape, such as valleys and watercourses, would be over come by spanning a network of pedestrian decks and express bus routes across existing topographical features. New recessed service roads would carry heavy transport. Because CLNT involved the expansion of existing housing, predominantly rows of terraces, RMJM remodelled the block layout to reduce traffic flow, incorporate footpaths and replace existing small scale industrial units with play spaces and garages.

The clarity of the notional city diagram became diluted when applied to existing subregion's conditions. The seven townships span between Longridge and Chorley with Preston as the main administrative, retail and service industry core and transport interchange. To the east, beyond the M6 motorway two greenfield new towns at Grimsargh and Longridge would accommodate 122,000 people, a significant population increase. These would specialise in education and recreation with Grimsargh also being a centre for welfare and Longridge an entertainment hub. South of Preston, the expansion of Walton would provide a further township for administration and education. Chorley's population would increase to 51,000 to become a culture and entertainment centre and Leyland, which RMJM identified as having most potential to expand and acquire new functions, would increase to 70,000, to become an education zone also requiring a new social and shopping area, possibly outside the present urban area. A lower density expansion at Cuerden would form a recreation centred district. The study concluded the area was capable of accommodating around half a million people.

In November 1973 the Development Corporation published a draft outline plan that required $£ 900$ million investment (at 1973 prices) from both private and public funders. 72,000 new homes were to be built in villages of about 3000-5000 people, grouped into districts of approximately 20,000. Substantial recreation areas were planned for the Ribble and Lostock Valleys including facilities for watersports, equestrianism and a zoo. These proposals then progressed into an outline 
master plan published in 1974, which was based on providing seven new district centres and eight new major employment areas across five townships (Grimsargh, Preston, Walton, Leyland and Chorley) by 2001. Facilities are not uniformly distributed, instead they are allocated according to hierarchy with Preston, Chorley and Leyland being prioritised.

Ideas of dispersal were progressed further at Civilia (1971), but these were combined with a return to the centralisation model. The planners, Michael Rowley and Rodney Carran, proposed linear expansion along a concentrated spine leading from a single central urban hub that was to act as a growth generator. This highdensity area would have a population of half a million and would have local centres injected at strategic points. A low-density lattice, as employed at Milton Keynes, was laid across this, capable of accommodating a similar population (De Wolfe, 1971). The study of theoretical diagrams to manage growth was hindered in 1976 when the national funding for new towns was revaluated as Ministers were concerned that inner city areas were starting to suffer economically. As a result, CLNT's population increase target significantly reduced to 23,000 people. During the 1980 s new towns were privatised and CLNT's Development Corporation was dissolved at the end of 1985.

Over a period of thirty years the strategy, configuration and scale of a new town for central Lancashire changed leaving an interesting architectural legacy dispersed across the region. In recent years the fate of CLNT's city-scale architecture has been debated, such as Preston Bus Station designed by the Building Design Partnership (1959-70), the largest bus station in the UK and second largest in Western Europe. This was CLNT's transport interchange that later became part of a wider retail, entertainment and office complex linked by raised walkways and subways to segregate pedestrian and vehicular movement. This included the Guild Hall and Charter Theatre by RMJM (1969-73), commissioned to commemorate the 1972 Preston Guild. Prior to CLNT's designation, Preston Corporation had commissioned Grenfell Baines and Hargreaves in 1959 (who later became Building Design Partnership in 1961) to design a new bus station and 500 capacity car park. The initial brief aspired to collate the town's dispersed termini of bus services. As the idea for a New Town in central Lancashire developed over the next six years, the size, role and importance of the bus station increased to create a prestigious public building that would be 'unrivalled in size and facilities in England [and] the Continent' (Architects' Journal, 1970). On completion the Architectural Review (1970) concluded that the building's 'imposing scale seems doubly right for a future mini-metropolis'. 171metres long, the bus station can accommodate 80 double-decker buses nose-on and 1100 cars on split-level decks above. Cantilevered curved edges of the concrete car decks create ribbed canopies to protect passenger platforms from weather. A central spine of passenger facilities and offices divides the ground floor concourse into two large waiting halls.

In Leyland a new district centre was commenced. Built projects include the Magistrates' Court and Library, 1970, on the northern side of Lancastergate, by Lancashire County Council Architects' Department. The Magistrates' Court is a dominant grey brick box topped with two copper roof pyramids and, adjacent to it, is the library, a single-storey brutalist building. A wide external staircase dominates the court's street elevation that has been articulated with a band of vertical concrete fins to define the windows and six single-leaf entrance doors. The staircase was designed to acknowledge an unbuilt pedestrianized shopping and entertainment precinct of twostorey buildings surrounding two civic public squares. Traffic along Lancastergate would be restricted to buses only and the area would be reached by a dual carriageway to the west.

At Cuerden the headquarters of Central Lancashire New Town's Development Corporation was first building constructed for the city following the new town's designation in 1970. The Development Corporation had selected Cuerden Hall, a historic building of local interest set within mature grounds, for its location as it is diplomatically placed in the centre of the designation area with no apparent favouritism to Preston, Chorley and Leyland. At the time Cuerden Hall was occupied by the armed forces and was due to be vacated 
in 1973, when it was to become a public amenity. Designed by RMJM, the building is noteworthy due to its rapid construction and its simple and elegant expression. The close working relationship of architect, engineer and quantity surveyor and the careful selection of materials enabled it to be completed in four months (Architects' Journal, 1972). Unified by a generous flat roof, the external envelope comprises a lightweight prefabricated timber and glass external walls set back from a framework of standard rolled steel sections to form a shaded cloister. Internally, two permanent central service cores subdivide an adaptable office space that offers views into the landscape. Originally the building employed an interesting use of colour. External uncased steelwork was painted yellow to contrast against the mature trees and shaded external walls. Internal block work partitions were left unplastered apart from cork-lined walls in the meeting rooms and the service cores which were plastered and painted red.

Although Central Lancashire New Town's part realisation was not as initially conceived, its theoretical model is relevant because it addressed the planning of a sub-region, rather than a single town or plot. Significantly its ambition was to provide a large-scale development composed by an inter-related series of self-contained communities, each with a clear identity or function, separated by a network of green space. It displayed ideas previously explored at Hook and Milton Keynes and later revisited at Civilia. Its presecence today can still be traced by its legacy of its cityscale buildings scattered across the region.

\section{References}

Arbour \& Associés (2001) Faubourg Québec, paramètres de développement urbain (Société de développement de Montréal, Montréal).

Architect's Journal (1961) 'Planning of a new town: the Hook study summarised', 6th December, 1095-8.

Architect's Journal (1970) 'Bus station and car park', 6th May, 1134.

Architect's Journal (1972) 'Cuerdon Pavilion, offices for Central Lancashire New Town Development Corporation, near Preston; Architects: R. Matthew Johnson-Marshall \& Partners', 13th September, 156, 597-610.

Architectural Review (1970) 'Services and disservices', July, 33.

Bendixson, T. (1969) 'Milton Keynes: the newest new town', Architectural Review, August, 103-8.

Brooke (1960) Letter from Mr. Brooke, Minister of Housing and Local Government, to Manchester Corporation cited in 'New town proposal for S. E. Lancashire: minister changes his mind', Guardian, 19th November 1960, 12.

Coates, U. A. (1964) Preliminary Technical Report on the Future Development of Central mid-Lancashire (with particular reference to the Chorley-Leyland area) 2nd September, 1-10.

Gibberd, F. (1947) 'Harlow New Town', The Builder, 19th December, 700.

Lancashire archives (1968) Central Lancashire New Town Proposals, file note NTC/4/1/82, 1st February.

Pearson, F. (1974) in Central Lancashire Development Corporation Outline Plan, 9.

Rodwin, L. (1956) The British New Towns Policy (Harvard University Press, Cambridge), 110.

De Wolfe, I. (1971) Civilia: The End of Suburban Man (The Architectural Press, London), 32. 